\title{
The Importance of Decision Making in Public Organizations
}

\author{
Que Duy Truong ${ }^{1}$, Nguyen Tien Manh ${ }^{1}$ \\ Faculty of Social Sciences and Humanities, Ton Duc Thang University, Vietnam \\ Received: January 3, 2021 \\ Received in Revised: January 22, 2021 \\ Accepted: February 1, 2021
}

\begin{abstract}
This study discusses the role of decision making in public organization. Comprehensive decision-making analysis is the application of methods within the setting of narrowing the choice in this conclusion that each decision requires examination utilizing elective strategies of investigation to limit down the elective choices. Issues that emerge are impediments that happen and influence vital things so that objectives are deferred. The presence of an issue gets to be degenerate and not in agreement with what was arranged, anticipated but not running appropriately. This can be what influences a choice that already had to analyze the issue, to begin with. Issues are more often than not recognized promptly but can be settled by analyzing them. It ought to be famous that somebody who makes the choice to create for the organization more often than not has inspirations that depend on the character of the elective confronting elective results and personal objectives. In the event that there are as well numerous choices, at that point ordinarily, individuals will make they possess decisionmaking system agreeing to their identity.
\end{abstract}

Keywords: Decision Making, Public Organization, Importance

\section{Introduction}

Decision making can be considered as a result or output of a mental or cognitive process that leads to the selection of a course of action among several available alternatives. Every decision-making process always produces one final choice. Decisions are made to achieve goals through implementation or action.

Each decision has different levels. Decisions usually have four levels, namely automatic decisions, decisions based on expected information, decisions based on considerations, and decisions based on multiple uncertainties. Automatic decisions are a form of decisions that are made very simply.

In essence, decision making is a systematic approach to a problem at hand. This systematic approach involves knowledge of the nature of the problem at hand, collecting facts and data relevant to the problem at hand, analyzing problems using facts and data, looking for alternative solutions, analyzing each alternative so that the most rational alternative is found, and the assessment of the results (Alavi \& Leidner, 2001; Koppenjan et al., 2004; Hardin et al., 2003). Achieved as a result of decisions taken

Decision making is part of the responsibilities of organizational leaders which require complete, correct and up to date information. Before a decision is made, alternatives are first formulated and made. One alternative is selected and then its implementation must be monitored. That the definition of decision making is the selection of two or more alternatives" according to this definition that to determine a decision must bring up alternative solutions, at least two or more solutions which will be determined then the best choice among them.

Comprehensive decision-making analysis is the application of techniques in the context of narrowing the selection in this opinion that each election requires analysis using alternative 
methods of analysis to narrow down the alternative options (Lai et al., 2002). In the decisionmaking process, nothing happens by accident. Decision making cannot be carried out "randomly" because the approach to decision making must be based on a certain systematics (Todd \& Benbasat, 1992). Certain systematics need to be based on: (1) Organizational capability means the availability of material resources that can be used to carry out the decisions taken. (2) Available manpower and qualifications to carry out decisions. (3) The philosophy espoused by the organization. (4) Internal and external environmental situations which according to calculations will affect the wheels of administration and management in the organization.

Whereas before a problem can be properly resolved, the nature of the problem must first be clearly known. It should be noted that in essence, decision making is solving problems in the best possible way. That the solution cannot be done only by seeking "inspiration" or by intuition, but also needs to be based on facts that are systematically collected, well processed and stored regularly so that the facts / data are truly reliable and still up to date. That the decisions taken are decisions that have been selected from various alternatives that have been thoroughly analyzed.

Decisions are made to solve problems. In solving problems, problem solving may make many decisions. Decisions are a series of actions that need to be followed in solving problems to avoid or reduce negative impacts, or to take advantage of opportunities (Simon, 1987; Reyna \& Farley, 2006). Decision making is very important for individuals and organizations. Making decisions is sometimes easy but more often than not it is very difficult. The ease or difficulty of making a decision depends on the number of alternatives available. The more alternatives available, the more difficult it will be to make a decision. The decisions taken have different levels. There are decisions that do not really affect the organization, but there are decisions that can determine the survival of the organization. Therefore, the explosives made decisions carefully and wisely.

\section{The Factors that Influence Decision Making}

Internal organization such as availability of funds, human resources, complete equipment, technology, and so on. Usually this factor is within an organization itself for the creation of a decision in the organization. External organizations such as socio-political conditions, economics, laws, and so on. This factor comes from outside that is involved in the organization. Availability of the necessary information. How much information there is or how complete and accurate is the information obtained to be considered in making the right decision. Personality and decision-making skills. In this factor, wisdom and decisiveness are needed in making decisions that are not detrimental.

\section{The Influence of External Pressure}

The influence of external pressure is a process that can affect decision making, because the process is fast or slow for decision makers depending on the amount of pressure received Wally \& Baum, 1994; Gonzalez et al., 2003). Sometimes decision makers are hesitant in making decisions, but the influence of outside pressure can speed up the decisions taken. This is due to the lack of assertiveness from organizational leaders in problem solving. So that a good personality is needed to deal with a pressure that comes especially from outside the organization.

\section{The Influence of Old Habits or Personal Traits}

Good and bad character factors that exist in a decision maker, are things that can influence this decision. In this case a decision maker will get used to his personal nature. This can be 
seen from the personality of a leader, how he makes decisions in dealing with problems. Of course, an organizational leader must be wise in behaving when there are problems and making decisions. It would be good if someone made a decision by looking at the situation around him not only based on personal policy so that it could benefit other parties.

\section{Influence from other Groups}

Other groups can also influence a decision because the group or organization has decisions that can be considered by the leaders of other organizations in addressing the problems and influence of other groups. This can also bring down the organization and prioritize the interests of the group. This can even lead to a split in the organization among its members. To avoid this, it takes strong solidarity between members and instills the principles that the organization has in every decision-making.

\section{The Experience Factor}

The experience factor of a decision maker is very important, because the person has a lot of experience, he will be brave in making decisions. This also relates to the expertise possessed by the leader or member because of the experience they have experienced. Experience can also be used as a lesson in making the right decisions for the organization.

Factors that need to be considered in decision making include things that are tangible or intangible, emotional and rational need to be taken into account in making decisions. Decisions can be determined with feelings but it will be better coupled with thoughts so that decisions can be accepted with feelings and can be explained through logic so that an imbalance does not arise.

Every decision must be used as material to achieve organizational goals. Because basically decisions are made to support the achievement of the goals of the organization. Every decision should not be oriented towards personal interests, but must prioritize the interests of the organization. It is less wise if decisions are made based on personal interests because in an organization there are many common interests. If it is only oriented to personal interests, decisions will not be achieved that will achieve goals in the organization.

Very rarely a satisfactory choice, therefore make counter alternatives. Choices must be made other than the main choice as a reference for decision making that can cover organizational interests. Decision making is a mental act from which this action must be transformed into a physical one. In other words, making decisions requires wisdom and decisiveness or courage to achieve goals after which the decision can be implemented in organizational life.

Effective decision making takes a long time. It is not uncommon to make the most appropriate decisions in an organization that takes a long time because of the many interests that exist in the organization and these decisions must cover all existing interests, so as not to harm anyone in the organization. Practical decision making is needed to get better results. Decisions should not be difficult, good decisions should be easy and have a positive impact on the organization.

Every decision should be institutionalized so that it is known that the decision is correct. In other words, decisions should be made with mutual consent by conducting negotiations and mutually agreed upon by various agreements. This agreement is made to anticipate if there is a discrepancy in the network of organizational activities after the decision. Each decision is the initiation of a series of activities in the next chain. Decisions are usually the basis for what will be done in organizational activities so that the good decisions can be considered carefully. 
Problems that arise are obstacles that occur and affect important things so that goals are delayed. The existence of a problem becomes deviant and not in accordance with what was planned, expected but not running properly. This is what affects a decision that previously had to analyze the problem first. Problems are usually not detected immediately, but can be resolved by analyzing them. Even before a problem occurs, you can do research related to important things that are predicted to arise. Therefore, a decision that is taken is certainly based on an analysis of the existing problem so that the final decision will be used.

Decision making is also influenced by certain situations that occur around them. It is more dominant to look like the atmosphere of the office at that time, how the condition of the company and other factors. The situation of a company that is declining in quality will certainly have a big influence in decision making.

Meanwhile, the condition is more dominated by the condition of the people who are directly involved, for example, there has been a massive employee strike. Decrease in employee performance at that time. So the decision is not easy to take and be certain, it must be thought about better so that there is no risk after making a decision.

\section{Approach to Decision Making with Community Organizations}

Individual appraisals take a big role in influencing the aspects of a decision. Each individual will view the decision based on various different sides. That is more to the confidence a person has in understanding the conditions and ends in making decisions. The assessments taken are based on background, childhood experiences, family factors and so on which does influence someone in their way of thinking and then how to judge something based on experiences and new thoughts.

In decision making, system thinking needs to be applied because it provides a comprehensive or comprehensive perspective on educational problems. Systems thinking sees problems systematically so that it can be used to assist managers in preparing a framework of thinking using a systems approach so that complex problems can be solved significantly in order to achieve the desired goals.

Decision making based on a person's level of rationality will produce an objective decision. Rationality is the view of people in seeing from a different side by considering various factors that exist. A person who uses his rationality in a decision is influenced by the situation and conditions that exist at that time. In addition, it will try to get thorough information before a decision is made. The next one will understand what the situation is like and analyze the consequences of a decision.

Decision making is usually carried out by individuals (individual decisions) and by organizations. Decisions by individuals take the form of decisions to participate and decisions to produce for the organization. In the case of a decision to participate, a person makes calculations about his encouragement and contribution to the organization (eg community organizations). it means that people respond to gifts from the organization and organizational expectations of one's functioning. If the gift from the organization is less than the contribution to the organization, people will always look for other alternatives, namely not participating in the organization, if the organization prize is the same as someone's donation, that person will seek additional information to decide whether or not to join the organization, and if the donation is smaller than the organizational reward, the person will participate in the organization. It should be noted that someone who makes the decision to produce for the organization usually has motivations that depend on the character of the alternative facing alternative consequences and individual goals. If there are too many alternatives, then usually people will make their own decision-making framework according to their personality. 


\section{Conclusion}

Decision making is part of the responsibilities of organizational leaders which require complete, correct and up to date information. Before a decision is made, alternatives are first formulated and made. One alternative is selected and then its implementation must be monitored. In decision making, system thinking needs to be applied because it provides a comprehensive perspective on educational problems. Systems thinking sees problems systematically so that it can be used to assist managers in preparing a framework of thinking using a systems approach so that complex problems can be solved significantly in order to achieve the desired goals. It should be noted that someone who makes the decision to produce for the organization usually has motivations that depend on the character of the alternative facing alternative consequences and individual goals. If there are too many alternatives, then usually people will make their own decision-making framework according to their personality.

\section{References}

Alavi, M., \& Leidner, D. E. (2001). Knowledge management and knowledge management systems: Conceptual foundations and research issues. MIS quarterly, 107-136.

Gonzalez, C., Lerch, J. F., \& Lebiere, C. (2003). Instance-based learning in dynamic decision making. Cognitive Science, 27(4), 591-635.

Hardin, R., Pateman, C., Weingast, B., \& Elkin, S. (2003). Deliberative policy analysis: understanding governance in the network society. Cambridge University Press.

Koppenjan, J. F. M., Koppenjan, J., \& Klijn, E. H. (2004). Managing uncertainties in networks: a network approach to problem solving and decision making. Psychology Press.

Lai, V. S., Wong, B. K., \& Cheung, W. (2002). Group decision making in a multiple criteria environment: A case using the AHP in software selection. European Journal of Operational Research, 137(1), 134-144.

Reyna, V. F., \& Farley, F. (2006). Risk and rationality in adolescent decision making: Implications for theory, practice, and public policy. Psychological science in the public interest, 7(1), 1-44.

Simon, H. A. (1987). Making management decisions: The role of intuition and emotion. Academy of Management Perspectives, 1(1), 57-64.

Todd, P., \& Benbasat, I. (1992). The use of information in decision making: An experimental investigation of the impact of computer-based decision aids. Mis Quarterly, 373-393.

Wally, S., \& Baum, J. R. (1994). Personal and structural determinants of the pace of strategic decision making. Academy of Management journal, 37(4), 932-956. 